Enfermagem Brasil 2018;17(6):619-26

https://doi.org/10.33233/eb.v17i6.2066

\title{
ARTIGO ORIGINAL \\ Percepção das puérperas de parto normal sobre violência obstétrica
}

Tayná de Paiva Marques Carvalho*, Carla Luzia França Araújo, D.Sc.**

*Enfermeira pós graduando em enfermagem obstétrica pela Escola de Enfermagem Anna Nery, Universidade Federal do Rio de Janeiro, "**Professora, Coordenadora do Programa de Residência de Enfermagem Obstétrica da Escola de Enfermagem Anna Nery, Universidade Federal do Rio de Janeiro

Recebido em 22 de janeiro de 2018; aceito em 03 de dezembro de 2018.

Endereço para correspondência: Tayná de Paiva Marques Carvalho, Estrada dos Bandeirantes 11219, 22783-116 Vargem Pequena RJ, E-mail: taynapmarques@gmail.com; Carla Luzia França Araujo: araujo.ufrj@gmail.com

\section{Resumo}

Introdução: A violência é vista como um problema social e de saúde, sendo classificada por diversas formas e tipos, gerando consequências e danos diversos em quem a sofre, sendo elas em nível físico, moral, emocional e espiritual. A violência obstétrica é um dos tipos de violência que abrange um conceito amplo e que atinge as mulheres durante a gravidez, parto, pós-parto e abortamento. Objetivo: Esta pesquisa tem o objetivo de analisar a percepção das puérperas sobre a violência obstétrica durante trabalho de parto e parto. Material e métodos: Trata-se de uma pesquisa exploratória e descritiva, com abordagem qualitativa realizada com 25 puérperas tendo como cenário um Hospital Maternidade do Rio de Janeiro. Resultados: Das participantes do estudo, a maioria das mulheres desconhecia o que era a violência obstétrica, e mesmo ela sendo vivenciada não era percebida como tal. Conclusão: Constatou-se que mesmo a violência obstétrica tratando de um tema ultimamente bastante abordado, ainda existe um grande déficit de conhecimento sobre ela entre as mulheres, sendo necessária a conscientização das mulheres sobre os seus direitos durante o ciclo gravídico puerperal.

Palavras-chave: parto normal, parto humanizado, enfermagem obstétrica.

\section{Abstract \\ Perception of normal labor performance on obstetric violence}

Introduction: Violence is seen as a social and health problem, being classified by different forms and types, generating diverse consequences and damages in those who suffer it, being they on a physical, moral, emotional and spiritual level. Obstetric violence is one type of violence, which encompasses a broad concept that affects women during pregnancy, childbirth, postpartum and abortion. Objective: This study aims to analyze the perception of puerperae on obstetric violence during labor and delivery. Methods: The study is an exploratory and descriptive study, with a qualitative approach performed with 25 puerperal women, based on a Maternity Hospital in Rio de Janeiro. Results: Of the study participants, most of the women were unaware of what obstetric violence was, and even if it was experienced it was not perceived as such. Conclusion: It was observed that even obstetric violence dealing with a topic that has been recently addressed, there is still a great lack of knowledge about it among women, and it is necessary to raise women's awareness about their rights during the puerperal pregnancy cycle.

Key-words: obstetric violence, normal birth, humanized delivery, obstetric nursing.

\section{Resumen}

\section{La percepción de las puérperas de parto normal sobre violencia obstétrica}

Introducción: La violencia es vista como un problema social y de salud, siendo clasificada por diversas formas y tipos, generando consecuencias y daños diversos en quien la sufre, siendo ellas a nivel físico, moral, emocional y espiritual. La violencia obstétrica es uno de los tipos de violencia, que abarca un concepto amplio y que afecta a las mujeres durante el embarazo, parto, posparto y aborto. Objetivo: Esta investigación tiene el objetivo de analizar la percepción de las puérperas sobre la violencia obstétrica durante el trabajo de parto y parto. Métodos: EI 
estudio se trata de una investigación exploratoria y descriptiva, con abordaje cualitativo realizado con 25 puérperas teniendo como escenario un Hospital Maternidad de Río de Janeiro. Resultados: De las participantes del estudio, la mayoría de las mujeres desconocía lo que era la violencia obstétrica, e incluso ella siendo vivenciada no era percibida como tal. Conclusión: Se constató que incluso la violencia obstétrica tratando de un tema últimamente bastante abordado, todavía existe un gran déficit de conocimiento sobre ella entre las mujeres, siendo necesaria la concientización de las mujeres sobre sus derechos durante el ciclo gravídico puerperal.

Palabras-clave: violencia obstétrica, parto normal, parto humanizado, enfermería obstétrica.

Introdução

Sabe-se que a violência se trata de um assunto que vem sendo vastamente debatido e abordado nos mais diferentes segmentos da sociedade contemporânea e abrange os aspectos sociais, culturais, as diferenças de sexo e raças, entre outros. É considerada como um problema social e de saúde, pode ser classificada de diversas formas e tipos, tem diferentes origens e consequências, podendo gerar danos de diversas gravidades em nível físico, moral, emocional e espiritual [1].

Um dos tipos de violência é a violência obstétrica, que tem um conceito amplo, e visa categorizar todos os procedimentos realizados durante a gravidez, parto, pós-parto e abortamento, sendo físicos ou não, os quais não são preconizados pelos princípios da humanização e medicina baseada em evidência [2].

De acordo com a Organização Mundial de Saúde (OMS), a violência obstétrica é uma "violação dos direitos humanos fundamentais", e agrupam maneiras de violência e prejuízos em meio aos cuidados obstétricos prestados pelo profissional de saúde, abrange maus tratos físicos, psicológicos e verbais. Além disso, ações desnecessárias e danosas como procedimento médico não consentido, recusa em administrar medicações, violação de privacidade, restrição da presença do acompanhante, recusa de internações nas instituições de saúde, cuidados negligentes durante o parto que leve a complicações evitáveis, uso demasiado de episiotomia, manobra de Kristeller e ocitocina, que podem acontecer em qualquer momento da gravidez, parto e pós-parto. Cabe ressaltar a exorbitância de cesariana, crescente no Brasil já algumas décadas, embora existindo iniciativas governamentais para melhorar esse quadro [3].

Diversas expressões já foram aproveitadas para assinalar o fenômeno, como: "violência no parto", "abuso obstétrico", "desrespeito e abuso", "violência de gênero no parto e aborto", "violência institucional de gênero no parto e aborto", "assistência desumanizada", "crueldade no parto", "violação dos direitos humanos das mulheres no parto" [4].

$\mathrm{O}$ aumento atual das pesquisas sobre a violência obstétrica e as experiências das mulheres durante a gravidez e parto mostra um quadro perturbador, já que mulheres do mundo inteiro sofrem abusos, maus tratos, negligência durante a assistência ao parto [3].

Nesse contexto, foi realizada uma pesquisa no Brasil, pela Fundação Perseu Abramo, mostrando que uma em cada quatro mulheres brasileiras que pariram, além de quase metade das que abortaram, descreveu ter sofrido de violência obstétrica [5].

A violência obstétrica em meio à gestação e parto pode ser determinada por: negação do atendimento à mulher, quando a mesma busca unidades de saúde como postos de saúde, ou quando the estabelece qualquer tipo de obstáculo em que está sendo concretizado o prénatal; comentários degradantes a mulher no que se alude a sua cor, idade, religião, escolaridade, classe social, estado civil, orientação sexual, quantidade de filhos; termos ofensivos até mesmo a sua família, sendo humilhada; agendar cesárea sem indicação fundamentada em evidências científicas, atendendo as necessidades e interesse do próprio médico [6].

Dentro deste contexto exposto acima, frases humilhantes e recorrentes que vão se reproduzindo de uma geração de médicos a outra, em maneira de piadas, e que humilham, toques dispensáveis e repetitivos, exibição do corpo da mulher em meio à maternidade, empecilho de se alimentar, de andar entre outras maneiras de agir [6].

Assim, esta maneira de violência vem sendo objeto de frequente atenção, inicialmente nos movimentos de batalha das mulheres, movimento contra a violência obstétrica e se ampliando ao meio acadêmico. No que se alude ao meio acadêmico, às áreas de humanas têm se preocupado mais com o assunto do que o campo da saúde que ainda permanece instruindo e aprendendo o parto exclusivamente como um acontecimento clínico com escassa 
proeminência na fisiologia e, principalmente, na assistência humanizada, abordando o parto como patologia. Esse evento que nunca pode ser imaginado e interpretado apenas do ponto de vista biológico, já que existem inúmeras dimensões culturais, psicológicas, de classe, gênero, etc. [6].

De fato, o parto trata-se de uma ocasião única e inesquecível na vida de uma mulher, e frente a isto, o cuidado despendido pelos profissionais da saúde precisa ser individual e regulado no protagonismo da mulher, portanto, tornando-o mais natural e humano presumível. Diferentemente de outros eventos que precisam de cuidados hospitalares, o procedimento de parturição é fisiológico, normal, precisando, na sua maioria, exclusivamente de apoio, acolhimento, atenção, e o mais essencial, a humanização [7].

A humanização se refere ao prestamento de uma assistência que apresente como prioridade a qualidade do cuidado, assegurando o respeito em relação aos direitos do paciente, sua personalidade e cultura, assim como a valorização do profissional que proporciona a assistência, constituindo um clima concreto nas instituições de saúde, que legitime o lado humano dos indivíduos envolvidos em todo o procedimento de cuidado e atenção [7].

A definição de atenção humanizada em meio à parturição conglomera conhecimentos, práticas e ações que objetivam assegurar o parto e nascimento saudáveis, considerando a prevenção da morbimortalidade materna e perinatal. Assim sendo, demonstra a necessidade de mudanças no entendimento do parto, como experiência humana e, para aquele que presta o atendimento, uma modificação em como atuar no período adequado perante o sofrimento do outro [7].

Este estudo tem como justificativa abordar uma temática que serve como impulso de um momento relevante para políticas públicas e saúde da mulher, visto que apesar de ser amplamente discutida e abordada, ainda é um algo real e vivenciado de forma abrangente entre as mulheres. Recentemente a OMS publicou uma declaração contra a violência obstétrica, reconhecendo-a como uma questão de saúde pública, "com o intuito de prevenir e eliminar os abusos, desrespeitos e maus tratos sofridos pelas mulheres durante toda a gravidez, porém, mais evidentes durante o parto nas instituições de saúde no mundo inteiro, convocando assim uma maior ação, diálogo, pesquisa e mobilização diante do tema." [3].

Ademais, no âmbito nacional, estão sendo realizadas inúmeras ações para o enfrentamento da violência obstétrica, pois, apesar de ser algo presente e deveras vivenciado, muitas mulheres não tem o conhecimento sobre o que de fato ela seja. Uma delas desenvolvida pela Defensoria Pública do Estado de São Paulo com a edição de uma cartilha que tem como objetivo alertar as mulheres sobre seus direitos, durante a gestação, parto e abortamento e as hipóteses de situações de violência, a realização de um plano de parto e até como denunciar os casos de violência sofridos, visando o conhecimento, e a identificação da violência pelas mulheres [8]. Outra ação que visa abolir a violência obstétrica é o Projeto de Lei $n^{\circ} 7633 / 2014$ [9] que tem como intuito dispor sobre o direito da mulher a uma assistência humanizada durante o ciclo gravídico-puerperal e visa penalizar os profissionais que cometeram a violência obstétrica. Recentemente foi aprovada a Lei $\mathrm{n}^{\circ} 17.097$ de 17 de janeiro de 2017 [10] que determina sobre a implantação de medidas de informação e proteção a gestante contra a violência obstétrica no Estado de Santa Catarina que demonstra avanços contra esse tipo de violência.

Dessa forma, essas e outras políticas e iniciativas visam buscar um resultado, a mudança frente à assistência realizada durante o trabalho de parto e parto, priorizando o conhecimento da mulher sobre a temática, cabe ressaltar que além das políticas, muitas mulheres que já sofreram a violência obstétrica através de associações e movimentos de mulheres buscam alertar outras mulheres, permitindo assim que com o conhecimento as mulheres combatam esse tipo de violência.

Dentro deste contexto, compete indagar como a mulher percebe a violência obstétrica. Logo, este artigo tem como objetivo analisar a percepção das puérperas de parto normal sobre a violência obstétrica.

Material e métodos

O presente estudo constitui-se de uma pesquisa exploratória e descritiva, com abordagem qualitativa. Realizado em um Hospital Maternidade no Município do Rio de Janeiro localizado na zona Oeste, sendo a única maternidade do Sistema Único de Saúde (SUS) inserida na área programática 4.0 da cidade do Rio de Janeiro e que constitui um dos campos de prática do Programa de Residência em Enfermagem Obstétrica. 
Trata-se de uma maternidade que realiza cerca de 450 partos/mês, com perfil de assistência materno infantil direcionado para o binômio materno fetal de risco, dado que possui tecnologia variada acoplada a um hospital geral com unidade de terapia intensiva de adulto e neonatal. Sua área física é formada por um espaço destinado ao atendimento à gestante com necessidade de cuidados de emergência/urgência obstétrica, de enfermaria clínica (obstétrica/neonatal), alojamento conjunto e uma área para cuidados específicos do recémnascido de risco. Há também local para atendimento ambulatorial de gestantes e crianças de risco.

As participantes do estudo foram as puérperas de parto normal, assistidas por médicos ou enfermeiros obstetras, que estavam internadas no Alojamento conjunto, no período de coleta de dados. Foram excluídas puérperas menores de 18 anos que pariram em outro local e foram transferidas para a maternidade e puérperas de parto cesariana.

A coleta de dados foi realizada no período de outubro a dezembro de 2016, por meio de entrevista individual. Para a entrevista foi utilizado um instrumento dividido em duas etapas. A primeira com questões abertas e fechadas para inicialmente traçar a caracterização das mulheres; e a segunda com as questões abertas para conduzir a entrevista especificamente sobre o tema em estudo. As entrevistas foram gravadas com um aparelho gravador, totalizando 25 puérperas.

Todas as determinações da Resolução 466/2012 do Conselho Nacional de Saúde do Ministério da Saúde foram respeitadas. O projeto foi submetido ao Comitê de Ética em Pesquisa da Escola de Enfermagem Anna Nery/UFRJ e aprovado com número CAAE 58702416.0.3001.5279. A coleta foi iniciada após emissão do parecer favorável do Comitê de Ética da Escola (CEP) da EEAN/HESFA/UFRJ e da Secretaria Municipal de Saúde do Rio de Janeiro. Todas as participantes assinaram o Termo de Consentimento Livre e Esclarecido (TCLE).

Após a coleta de dados, foi seguida a seguinte ordem: os registros das entrevistas gravadas, transcritas, classificadas e categorizadas conforme os temas, e analisados pela orientação de análise temática categorial, que como o próprio nome diz o conceito central é o tema [11].

A trajetória de análise começou com pré-análise que constitui na leitura compreensiva do material selecionado que possibilitou uma visão do conjunto, analisando as particularidades e elaborando pressupostos para a análise e interpretação do material, escolher formas de classificação e determinar os conceitos teóricos que iriam orientar a análise. O próximo passo foi a exploração do material, que é a análise propriamente dita, que consiste em determinar e categorizar, reagrupando as partes por tema encontrado. Em seguida, recortou-se trecho de depoimentos e neles foram identificadas as ideias explicitas e implícitas e, por último, fez-se uma síntese interpretativa que pudesse interagir com o objeto de estudo, base teórica e dados empíricos [11].

Resultados

\section{Compreensão da puérpera sobre o que é violência obstétrica}

Ao questionar as puérperas sobre o que ela compreende ser violência obstétrica, percebeu-se que a violência obstétrica foi descrita em distintas formas que acabam todas realmente englobando o significado de violência obstétrica. As interpretações mais utilizadas foram não respeitar a opinião, negar os direitos, não fornecer informações, gritos, tratar de forma ignorante, maus tratos, privar o direito ao acompanhante, realizar procedimentos sem consentimento, negligenciar a assistência, não dar atenção, tratar com descaso, fazer pouco caso da dor, tratamento desumanizado, receber toques repetitivos, não escutar a paciente, não procurar saber seus anseios, não mostrar empatia, comentários constrangedores e romper a bolsa. Porém também foi colocado como violência o desrespeito ao aguardar o trabalho de parto demorado e "forçar" o parto normal.

“Ah! Maltratar a pessoa, deixar a pessoa sozinha na sala de parto” (P09).

"Humm... Negar os direitos né? Machucar ou fazer alguma coisa que a gente não queira [...]" (P10). 


\begin{abstract}
"Você não respeitar a vontade da mãe que tá em trabalho de parto [...] o fato de você não esclarecer as coisas que estão acontecendo pra mãe [...] um médico cortar a mãe sem falar, sem avisar, sem explicar o porquê que precisa cortar, sem perguntar a ela se ela quer que corte ou não. Antigamente existia hoje eu não sei se acontece ainda, mais subir em cima da mãe pra forçar o bebê pra baixo. Deixar a mãe no leito em trabalho de parto e não ir lá vê se tá tudo bem [...]" (P12).
\end{abstract}

"[...] é quando eles fazem algo que não seja só consentido, é algo que prejudique de alguma forma, entendeu? [...] é eles violarem os seus direitos, é tratar você com descaso [...] é fazer pouco caso da sua dor, do que você tá sentindo, do que você tá falando [...] Eu acho que as pessoas deveriam ter mais respeito pela dor do outro e na verdade muitos não têm. Fazem aquela: Ah, fez o filho, não foi bom botar pra dentro? Mais não bota pra dentro igual bota pra fora não [...]" (P19).

O que se consegue avaliar diante do exposto é que a grande maioria coloca como violência obstétrica apenas fatos referentes à violência verbal e emocional, houve apenas um relato que envolveu a violência física (romper a bolsa), cabe ressaltar, também, que os procedimentos realizados durante o parto de forma desnecessária como a episiotomia, manobra de Kristeller, uso indiscriminado de ocitocina, foram relatados como violência obstétrica, apenas por duas das entrevistadas, um número bem reduzido, o que nos indica que não são percebidos como violência pela grande maioria.

Outro quesito questionado foi se as entrevistadas já haviam ouvido falar sobre o termo, violência obstétrica e para admiração à minoria desconhecia o tema ou termo.

E quando aqueles que já tinham conhecimento sobre o que é a violência obstétrica, foram analisados através de onde ou como obteve esse conhecimento, foi relatado, então, a visita na maternidade realizada pela Cegonha Carioca, entrevistas e documentários na televisão, e na internet em grupo em rede sociais, blogs e no pré-natal onde foi incentivado realizar a denúncia em caso de ser violentada.

Percepção da puérpera com relação à assistência recebida e a vivência de violência obstétrica

A grande maioria não relacionou a assistência e os procedimentos recebidos durante todo o período de parturição como violência obstétrica, avaliando a assistência recebida positivamente, portanto não se sentindo violentada.

"Não, nenhuma vez, a equipe me atendeu muito bem" (P03.)

"Não. Graças a Deus elas foram bem doces, calmas, conversando, ajudando. Gostei muito" (P05).

"Não, em nenhum momento [...] muito pelo contrário, a equipe sempre foi muito clara [...] então eu me senti muito bem atendida e não me senti de nenhuma maneira violentada [...]" (P12).

"Não, eles me ajudaram bastante [...] me ajudaram a segurar minha perna pra mim fazer força, e tavam me posicionando pros lados, pra ver qual era o lado que eu sentia melhor pra botar ele pra fora" $(\mathrm{P} 16)$.

Houve puérperas que avaliaram a assistência e procedimentos recebidos de forma negativa, porém não consideraram como violências obstétricas, consequentemente, não se sentiram violentadas, portanto cabe ressaltar que o que foi considerado como negativo é considerado violência obstétrica.

"Não, a única coisa que eu não gostei foi, pedi a enfermeira pra dá o toque ali pra eu saber [...] se a enfermeira tá ali, a gente somos o paciente, ela tem que examinar a gente [...]" (P11).

"Não, assim, quando eu cheguei aqui e fui fazer exame de toque, foi ai que eu não gostei, e quando eu entrei na sala de parto que veio a pessoa pra vê quanto que eu tava de dilatação [...] teve uma que não me tratou muito bem" (P14).

Houve também duas puérperas que consideraram ter recebido uma assistência vista como violência obstétrica, portanto sentiram-se violentada durante o processo de parturição. 
"Ah, eu penso que foi o que aconteceu, assim, que eu pedi pra me rasgarem e, "não a gente não pode a criança que tem que vir rasgando tudo", porque eu pedi muito entendeu? [...] e o toque, que toda hora vinha um e dava toque, entendeu? E aquilo doía entendeu? [...] Mais assim eu já sei como já é, eu por dentro, já sei como é que sou [...] se não realmente não colocar o soro não delata entendeu? [...] eu acho que foi pior por causa dos pontos, que ela veio rasgando tudo, dos outros quatros eu nunca tive que tomar ponto lá, assim lá trás" (P08).

"Com certeza, que você pede pra verificar sua pressão porque você ta passando mal, que nem eu, sou hipertensa, minha irmã teve que sair e pedi, porque ninguém veio [...] esse procedimento de deixar você sozinha, só com o acompanhante, eu acho isso violência. Porque o acompanhante não sabe o que fazer com você, ai quando chama a médica, aí ela "Ah"! Não faz força! Espera! Não botei a luva. Porque se ela tivesse, ali junto com a gente, ela estaria preparada." (P20).

Examinando o relato da puérpera (P08), pode-se perceber que a assistência que foi oferecida, foi uma assistência voltada para boas práticas, onde o uso da ocitocina não foi realizado indiscriminadamente, não houve a episiotomia de rotina, portanto provavelmente essa mulher se "acostumou" em vivenciar a experiência do parto com a utilização de intervenções desnecessárias, considerando erroneamente essas práticas como violência.

Desta maneira, a percepção das mulheres entrevistadas sobre seu parto e a violência obstétrica está baseada nas experiências, histórias de vida e expectativas e reflete diante de um padrão social construído o que coincide com a aceitação e banalização da violência vivenciada.

Diante do exposto, é evidente que a expectativa das mulheres no parto é marcada por uma diversidade social alterando-se conforme características culturais, sociais, religiosas e étnicas, sendo o parto um ato cultural que é refletido pelos valores sociais prevalentes de uma sociedade [12].

Dessa forma, a violência que ocorre no cenário do parto é, frequentemente, considerada como parte da rotina dos serviços de saúde e incorporada aos fluxos das maternidades. Não sendo entendida por grande parte das mulheres como um ato violento e sim como algo rotineiro e comum [13-15].

Portanto, mesmo quando a violência obstétrica acontece é vista de forma naturalizada e banalizada, tendo muito pouca visibilidade, por ser um tema estigmatizado. A percepção de violência também está diretamente relacionada à ação simbólica. Essa violência acontece durante um momento de vulnerabilidade, e é associada como uma agressão como qualquer outra, porém como na maioria das vezes ela vai ser executada pelo profissional de saúde, é vista como uma conduta normal. Cabe ainda destacar que a compreensão sobre a violência obstétrica deve ser considerada, principalmente, envolvendo aspectos econômicos, sociais e todo contexto histórico [12,15,16].

Porém, para que essa vivência seja experimentada de forma negativa ou positiva, irá depender de inúmeros fatores inerentes à mulher e à gestação, como experiência em partos anteriores, experiências das mulheres próximas, a segurança em relação de si mesma ao que se refere ao seu papel de mulher e mãe, entre outros, e os que são ligados diretamente ao sistema de saúde como uma assistência de pré-natal que envolveu ou não um apropriado preparo físico e emocional para o parto [14].

A medicalização evidente no trabalho de parto e parto vem retirando o protagonismo da mulher, fazendo do profissional da saúde o ator principal dessa experiência, enfatizando o aspecto patológico e biológico da gravidez, e intensificando as relações desiguais, sendo capaz de contribuir para o grande número de intervenções desnecessárias [14].

As mulheres estão sendo visualizadas como uma máquina cujo operador é o profissional de saúde, propondo ser o detentor dos saberes, assim negligenciando informações e os direitos referentes à gestação e ao parto, impedindo-as de optarem pela posição a qual querem parir, de mostrarem suas preferências, seus desejos, deixando-as mais vulneráveis à violência. Isso nada mais é que um tipo de violência, retratada pela hierarquia e dominação do saber médico sobre o corpo da mulher, oprimindo diretamente a autonomia ao respeito daquilo que exclusivamente pertence a elas e aos seus corpos [2].

Portanto, a recomendação é prestar uma assistência humanizada baseada em evidência, na qual o discurso esteja juntamente com a prática, proporcionando um parto verdadeiramente humanizado. A humanização abrange pelo menos dois fatores fundamentais: 
o primeiro, a consciência de que é dever da unidade de saúde receber a mulher com dignidade, determinando que os profissionais de saúde possuam uma atitude ética e solidária e que a instituição se organize visando criar um ambiente acolhedor, instituindo rotinas para banir o isolamento imposto à mulher; e o segundo fator reporta-se a adesão de medidas e procedimentos com benefícios comprovados para o acompanhamento do parto, evitando intervenções desnecessárias, que embora corriqueiramente realizado, não oferecem nenhum benefício, pelo contrário podem acarretar maiores riscos [17].

Logo, a humanização da assistência ao parto consiste nos desejos das mulheres de que a vivência do parto aconteça conforme suas perspectivas, sendo assim, os profissionais que prestam a assistência ao parto devem respeitar a autonomia e a individualidade [2].

Conclusão

Através do presente estudo pode-se concluir que verdadeiramente as mulheres desconhecem o que é a violência obstétrica, sendo identificada apenas em momentos que ocorrem como violência verbal e maus tratos, portanto não percebida diante da realização de procedimentos desnecessários, pois mesmo ao ser exposta à vivência da violência a parturiente não a considerada como tal. Esses procedimentos, desnecessários na maioria das vezes, são vistos como auxílio para facilitar o parto, e, quando essa "colaboração" não é realizada, consequentemente a assistência recebida não é percebida como eficiente. Demonstrando, assim, o grande déficit de conhecimento das mulheres sobre os seus direitos a uma assistência ao parto humanizada e, sobretudo, baseada em evidências.

A principal forma de combate da violência obstétrica é através do conhecimento das mulheres em relação ao processo de parturição. A obtenção dessas informações acontece geralmente durante o pré-natal, pois é o momento em que se deve estimular a preparação para o parto.

Sugere-se que os resultados e sua análise possam justificar uma discussão interna com os profissionais, para que busquem qualificação e estratégias para conscientizar as mulheres quanto ao direito a uma assistência humanizada, censurando a violência obstétrica e buscando melhorar o desempenho com intuito de propagar as boas práticas obstétricas, prestando uma assistência livre de violência obstétrica.

O estudo pode apresentar como limite ter sido realizado em apenas uma maternidade, porém acredita-se que essa seja uma realidade encontrada em outras maternidades de outros municípios e estada brasileira.

Referências

1. Zanardo GLP, Calderón M, Nadal AHR, Habigzang LF. Violência obstétrica no Brasil: uma revisão narrativa. Psicol Soc 2017;29: e155043. https://doi.org/10.1590/18070310/2017v29155043.

2. Andrade BP, Aggio CM. Violência obstétrica: a dor que cala. Anais do III Simpósio Gênero e Políticas Públicas. Londrina: Universidade Estadual de Londrina; 2014.

3. Organização Mundial da Saúde. Declaração da OMS: Prevenção e eliminação de abusos, desrespeito e maus-tratos durante o parto em instituições de saúde. 2014. [citado 2017 Dez 12]. Disponível em: http://apps.who.int/iris/bitstream/10665/134588/3/WHO RHR 14.23 por.pdf

4. Tesser CD, Knobel R, Andrezzo HFA, Diniz SD. Violência obstétrica e prevenção quaternária: o que é e o que fazer. Rev Bras Med Fam Comunidade 2015;10(35).

5. Venturi W. Mulheres brasileiras e gênero nos espaços públicos e privado. Fundação Perseu Abramo e SESC [Internet]; 2010.

6. Miranda JZ. Violência obstétrica: uma contribuição para o debate acerca do empoderamento feminino. Rev Rene 2012;15(2).

7. Silva MG, Marcelino MC, Rodrigues LSP, Toro RC, Shimo, AKK. Violência obstétrica na visão de enfermeiras obstetras. Rev Rene 2014;15(4).

8. Defensoria Pública do Estado de São Paulo. Conservando sobre violência obstétrica; 2015. [citado 2017 Dez 12]. Disponível em: http://www.defensoria.sp.gov.br/dpesp/repositorio/34/documentos/cartilhas/Cartilha VO .pdf

9. Brasil. Projeto de Lei $n^{\circ} 7633 / 2014$. Dispõe sobre a humanização da assistência à mulher e ao neonato durante o ciclo gravídico-puerperal e dá outras providências. 
10. Brasil. Lei $n^{\circ} 17.097 / 2017$. Dispõe sobre a implantação de medidas de informação proteção à gestante e parturiente contra a violência obstétrica no Estado de Santa Catarina.

11. Minayo MCS, (org). Pesquisa social: teoria, método e criatividade. $14^{a}$ ed. Rio de Janeiro: Vozes; 2014.

12. Gama A et al. Representações e experiências das mulheres sobre a assistência ao parto vaginal e cesárea em maternidades pública e privada. Cad Saúde Pública 2009;25(11):2480-8. https://doi.org/10.1590/s0102-311x2009001100017

13. Queiroga JS, Silva RV. A violência obstétrica no parto: uma realidade brasileira. Grupo temático: Direitos Humanos, Diversidade Humana e Serviço Social; 2015.

14. Rocha MJ, Grisi EP. Violência obstétrica e suas influências na vida de mulheres que vivenciaram essa realidade. Id on Line 2017;11(38). https://doi.org/10.14295/idonline.v11i38.931

15. Aguiar JMD, Oliveira AFL. Violência institucional em maternidades públicas sob a ótica das usuárias. Interface - Comunicação Saúde Educação 2011;15(36):79-91. https://doi.org/10.1590/s1414-32832010005000035

16. Estumano VKC, Melo LGS, Rodrigues PB, Coelho ACR. Violência obstétrica no Brasil: casos cada vez mais frequentes. Revista Recien 2017;7(19):83-91.

17. Brasil. Ministério da Saúde. Cadernos Humaniza SUS: Humanização do parto e nascimento. Brasília: Ministério da Saúde; 2014. 